\title{
A young female with polycythemia: Pearls in the lung
}

\section{Avneet Garg® ${ }^{\circledR}$, Vinita Jindal, Khushdeep Singla, Manjot Kaur}

Adesh Institute of Medical Sciences and Research, Bathinda, Punjab, India

A 35 year-old female presented to the Pulmonary Medicine OPD with a history of progressive dyspnea, malaise, weakness and easy fatigability for the last 5-6 months. On examination, she had clubbing and redness on her face. She had stable vitals but low room air oxygen saturation on pulse oximetry $\left(\mathrm{SpO}_{2}\right.$ of $\left.85 \%\right)$. Chest examination was normal. Laboratory parameters showed $\mathrm{Hb}-19.2 \mathrm{~g} / \mathrm{dl}$ and hematocrit $-57 \%$. Other hematologic and biochemical parameters were within normal limits. Her chest X-ray showed right upper lobe infiltrates (Figure 1A-B) and she was prescribed empirical anti-tubercular therapy (ATT) by an outside practitioner based on clinical and radiological findings. Echocardiography (ECHO) and an ultrasound of the abdomen were normal. Screening for polycythemia conducted during the initial evaluation revealed high erythropoietin levels, absent Jak-2 mutation, and no findings to suggest plasma volume contraction. She had no improvement of symptoms after 1 month of ATT. As a result, the patient was evaluated further. ABG measurements showed ph $-7.41, \mathrm{pCO}_{2}-39, \mathrm{pO}_{2}-49$, and $\mathrm{HCO}_{3}-23$. A contrast ECHO was ordered to rule out any blood shunting as infiltrates on chest X-ray were inconsistent with the degree of hypoxemia and polycythemia. ECHO revealed appearance of air bubbles in the left atrium after 3 cycles of heart beats. A subsequently performed contrast-enhanced computed tomography of the chest along with CT pulmonary angiography (Figure 1C-F) showed pulmonary arteriovenous malformations. A CT scan of the brain was normal. A colour doppler of bilateral upper and lower limbs (arterial and venous) did not show any thrombi. Hence, the final diagnosis was pulmonary arteriovenous malformations (PAVMs).

Pulmonary arteriovenous malformations are rare pulmonary vascular anomalies and are mostly asymptomatic but can cause dyspnea based on the degree of left-to-right shunting and the severity of hypoxemia [1]. Although uncommon, polycythemia can be a presenting manifestation of PAVMs due to chronic hypoxemia [2]. Paradoxical emboli can cause stroke or cerebral abscesses, particularly if previously undiagnosed. The most common cause of PAVMs is HHT (hereditary hemorrhagic telangiectasia). PAVMs may be solitary or multiple and lower lobes are most commonly affected. The right upper lobe is rarely involved [1]. In our case,
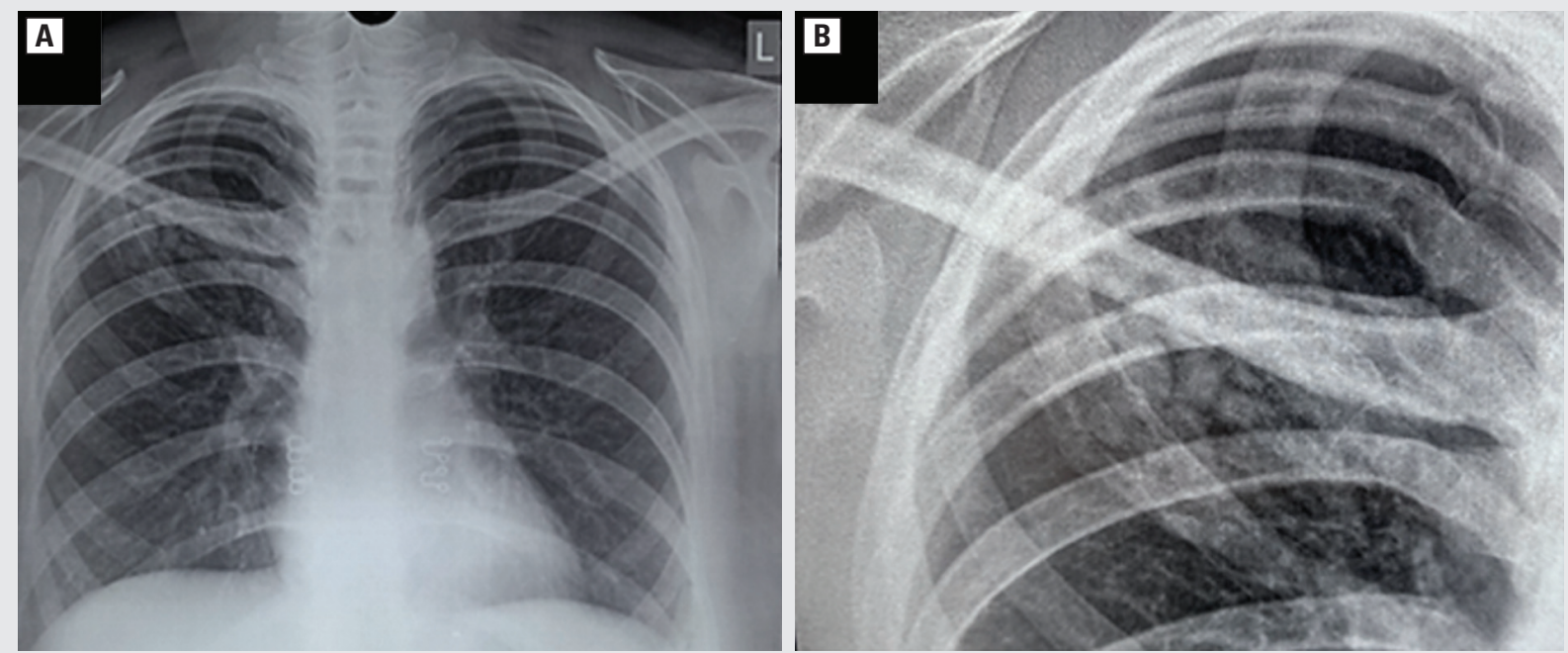

Figure 1. A. Chest $\mathrm{X}$-ray posteroanterior view showing a lobulated opacity in the right upper zone. B. Magnified view showing curvilinear opacities extending from the hilum suggestive of a pulmonary arteriovenous malformations (AVM)

Address for correspondence: Avneet Garg, Adesh Institute of Medical Sciences and Research, Bathinda, Punjab, India; e-mail: dravneetgarg@gmail.com Conflict of interest: None declared

DOI: 10.5603/ARM.a2021.0077 | Received: 04.04.2021 | Copyright (C) 2021 PTChP | ISSN 2451-4934 | e-ISSN 2543-6031

This article is available in open access under Creative Common Attribution-Non-Commercial-No Derivatives 4.0 International (CC BY-NC-ND 4.0) license, allowing to download articles and share them with others as long as they credit the authors and the publisher, but without permission to change them in any way or use them commercially. 

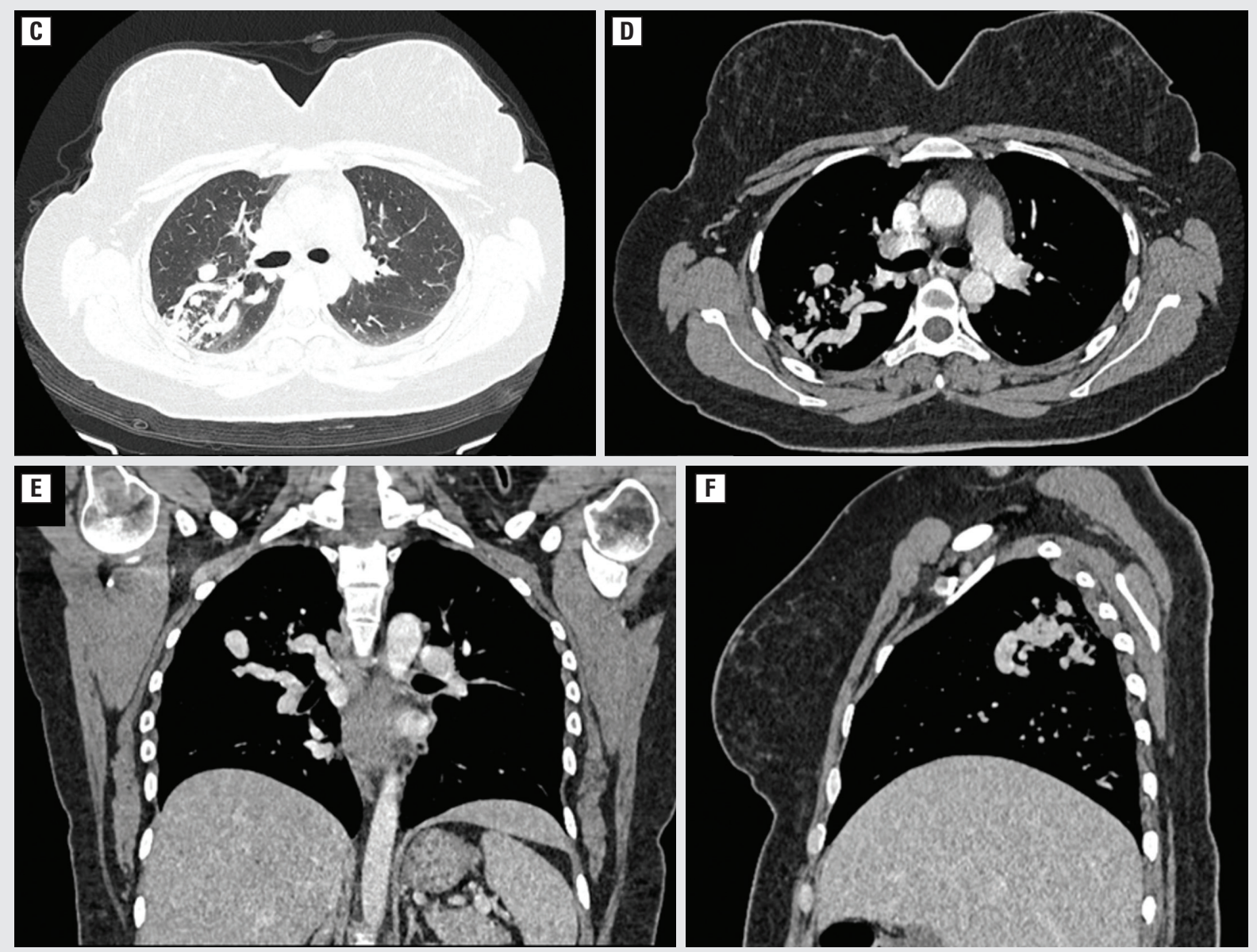

Figure 1. C. Axial chest computed tomography (CT) pulmonary window showing tubular branching opacities in the posterior segment of the right upper lobe. D. Axial CT mediastinal window showing a tuft of vessels. E. Coronal CT showing a pulmonary AVM with a feeding artery and draining vein. F. Sagittal CT showing a pulmonary AVM

the unusual location of this rare entity led to a false diagnosis of pulmonary tuberculosis. Chest radiographic features classically present are sharply defined non-specific round to oval opacities of uniform density that are frequently lobulated and range in size from 1-5 cm [3]. Contrast echocardiography is a highly sensitive tool for diagnosis, but CT pulmonary angiography remains the gold standard [4]. Treatment options include embolization and surgical excision [5].

The diagnosis of PAVM as a cause of polycythemia in a young female and its unusual location in the lungs leading to an incorrect diagnosis of pulmonary tuberculosis makes this case rare and interesting.

\section{References:}

1. Prager RL, Law KH, Bender HW. Arteriovenous fistula of the lung. Ann Thorac Surg. 1983; 36(2): 231-239, doi: 10.1016/s00034975(10)60465-1, indexed in Pubmed: 6349562.

2. Smith HL, Horton B. Arteriovenous fistula of the lung associated with polycythemia vera: report of a case in which the diagnosis was made clinically. Am Heart J. 1939; 18(5): 589-592, doi: 10.1016/s0002-8703(39)90882-3.

3. Dines DE, Arms RA, Bernatz PE, et al. Pulmonary arteriovenous fistulas. Mayo Clin Proc. 1974; 49(7): 460-465, indexed in Pubmed: $\underline{4834927 .}$.

4. Barzilai B, Waggoner AD, Spessert C, et al. Waggoner AD, Spesset C, Two-dimensional contrast echocardiography in the defection and follow up of congenital pulmonary arteriovenous malformations. Am J Cardiol. 1991; 68(15): 1507-1510, doi: 10.1016/00029149(91)90287-u, indexed in Pubmed: 1746435.

5. Dutton JA, Jackson JE, Hughes JM, et al. Pulmonary arteriovenous malformations: results of treatment with coil embolization in 53 patients. AJR Am J Roentgenol. 1995; 165(5): 1119-1125, doi: 10.2214/ajr.165.5.7572487, indexed in Pubmed: $\underline{7572487 .}$ 